The forenoon of Wednesday, June 24, was taken up by the conferring of honorary degrees on a number of delegates in the Great Hall of the University. Among those who were thus honoured may be mentioned Sir Henry Dale, Prof. Herbert Freundlich (University College, London), and Dr. Clarke (University of Oxford). At midday the delegates and their ladies were entertained to lunch in the cloisters and cloister garden of the Cathedral Church, after which they witnessed the march past the University of the students' "Masquerade". This was a dramatic procession of pikemen, mounted knights, etc., of which the special feature was the "Prince of Orange" and his retinue.

In the afternoon, there was a very enjoyable excursion (by autobus) into the province of Utrecht, including a visit to Hilversum and its new town hall (a fine building in the modern unadorned style) and tea in the park of the Chateau Deynselburg, given by Madame and Dr. S. Jacob. On returning to Utrecht, the guests paid homage to the "Prince of Orange", who held a Court.

The day concluded with a gala concert in the Tivoli Concert Hall, conducted by the famous Willem Mengelberg. The programme was: Sol Justitiae: a hymn dedicated to the University of Utrecht on the occasion of the third centenary (composed by Dr. H. E. Enthoven); Piet Hein : a Dutch rhapsody (composed by Dr. P. G. van Anrooy); Overture to the "Taming of the Shrew" (composed by Dr. Joh. Wagenaar); Beethoven's Fifth Symphony.

The music was well played by the municipal orchestra under the spirited leadership of Mengelberg. An amusing incident was the arrival of the "Prince of Orange" and his retinue. Even the great Mengelberg had to come down from his rostrum and pay homage !

Thus ended three wonderful days of lavish Dutch hospitality, academic ceremony and students' pageantry. As if in remembrance of the University motto, Sol Justitiae, illustra nos, the sun shone brightly on the gay scene of scarlet gowns, whiteplumed horses, knights on horseback and the great Prince of Orange. The professors of the University amply sustained the honour of their city and their country in offering very kind private hospitality to many of the invited guests.

It was a great demonstration of the universality of learning, of the brotherhood of truth and freedom. As one stood in the peaceful cloister garden and listened to the carillons from the ancient tower, the message of a noble civilization resounded in one's ears. One was glad to feel that Holland had kept the sweet music of her old carillons and in the benign tolerance of a greater humanity had won the freedom of her soul.

F. G. Donnan.

\title{
Fractures in Metals and Brittle Materials
}

\begin{abstract}
A
DISCUSSION on "Fractures in Metals and Society on Thursday, June 11. Many points of importance were brought out in this interesting discussion, and it is perhaps difficult in the small space of a general article to do justice to them.

In introducing the subject, Dr. H. J. Gough presented a review of the present position of knowledge in regard to the understanding of the mechanism of failure. As regards metals, he holds that in view of their essentially crystalline structure the required physical explanation must be in terms of atomic structure before any real progress in ideas can be achieved. Stripped of non-essentials, the problem is that of obtaining an understanding of plastic deformation and a realization of the exact conditions under which a crack is formed. He emphasized the disability of not having available a satisfactory conception of the laws of cohesion in the metallic state, and the extreme value of any new contribution in this direction. Elasticity is an expected property in a metallic crystalline aggregate, but plasticity is a property which is extremely difficult, at the present time, to understand.

The study of single crystals is very helpful since the processes of deformation and fracture are characteristics associated with the crystal structure, and effects in erystal aggregates are modifications of the effects occurring in single crystals. The geometrical aspects of deformation are established, but give no information on the mechanism of fracture. While stressing the fact that the characteristies of deformation and fracture are probably capable of explanation in terms of single crystals, it must be remembered that the strength of polycrystalline aggregates depends to some extent on crystal size,
\end{abstract}

so that an understanding of the part played by the crystal boundaries is a very important factor in the solution of the whole problem. No established explanation has yet been provided in regard to workhardening, strain hysteresis, twinning and the process of conversion of strain energy indefinitely into heat energy.

Assuming that the mechanism of fracture is essentially a property of the individual crystals, Gough and Wood have described, in a recent paper, an investigation by $\mathrm{X}$-ray methods into the physical system prevailing after different numbers of cycles in fatigue tests. It would appear that at fracture the physical system is the same under all conditions. Under a safe range of stress the damage to the crystal structure is not progressive, but a stable state is reached, whereas under an unsafe range of stress progressive change takes place. The changes in the neighbourhood of the ultimate fatigue crack are characteristic and exactly similar under all unsafe ranges of stress, and in this area the original structure is destroyed and new crystallites formed. This appears to be a definite advance in knowledge.

Prof. G. I. Taylor confined his remarks chiefly to the more precise mathematical theory of internal flaws. If one crystal is deformed, and hardening is produced in the crystal, additional stresses are im. posed on the surrounding crystals, which therefore tend to become deformed. In steel at the yield point the stress is reduced on deformation. In this case the deformation tends to proceed in the same crystal and an irregular deformation results.

If the material has internal flaws-such as might be represented by small spherical and ellipsoidal cavities - the stresses acting locally are increased. Failure under these local stresses would be expected 
to occur when certain critical combinations of shear and direct stress are reached. (The exact relationships between shear and direct stress which follows from Mohr's hypothesis and from that of von Mises differ somewhat.) A special case is that where the cavity is filled with a material. For simple shapes of cavity, the stresses can be calculated, and one result is that if a flaw is assumed to be ellipsoidal, then the greatest concentration of stress may occur with the direction of the flaw at $45^{\circ}$ or at right angles to the direction of principal stresses, according to the relative compressibility of the 'inclusion'.

Prof. L. N. G. Filon dealt chiefly with the different types of fracture which occur in solids, and illustrated his remarks with a large number of fractures in cast iron and glass. In ductile materials, slip does not always occur at $45^{\circ}$ to the principal stresses. A fracture in a strip of mild steel broken in tension showed a fracture at approximately $60^{\circ}$ to the line of the principal stresses. This was not due to any assymetrical properties of the steel, since a second slip line clearly shown by the material was exactly symmetrical with the first. In cast iron, brittle fractures can be obtained by a bending operation in which pure tension is applied to some parts of the material, and pure longitudinal compression in other parts. In this case fracture occurs at right angles to the stress lines. A curious 'staircase' fracture has been observed in these brittle materials in which the fracture began at right angles to the tension, but after passing through the material for some distance, branched along the line of tension, and branched back into the original direction and gave a step. In some cases several steps were observed. The conclusion reached was that in the same material the type of fracture obtained depends on the method of application of stress.

The possible effects of sub-microscopic eracks was the chief point discussed by Prof. E. N. da C. Andrade. $\mathrm{He}$ considers that the existence of surface cracks has been well established in three series of experiments. A strip of mica loaded so that the edges are stress free has a strength of about ten times the normal value. Andrade and Martindale in experiments on thin metal films on glass, diamond or other substance, have found that recrystallization proceeds on definite lines on the surface. These lines do not appear when the film is produced on the very perfect cleavage faces of mica. Indirect evidence of these surface cracks is afforded by experiments of Roscoe on cadmium wire, which had its critical shear stress increased to double the normal value when coated with a thin film of oxide a few molecules thick. It is well known that freshly drawn threads of quartz and glass are stronger than old threads. Griffiths believes this to be due to the absence of cracks in the freshly formed threads. In concluding, Prof. Andrade indicated briefly some of the difficulties of forming a theory of plastic deformation. In plastic materials, twinning and gliding take place on the twinned material in a way which is very complicated even in single crystals.

Dr. W. H. Hatfield said that the stress which may be safely applied is far removed from the stress which produces fracture, and that from the point of view of the engineer and metallurgist, the actual mechanism of fracture is less important than a satisfactory explanation of the means which are effective in increasing the safe range of stress. In iron, the fatigue range of the crystalline aggregate is increased and the stress to produce initial plastic deformation is also increased by 'sprinkling' particles of a hard, brittle substance, carbide of iron, through the mass of the ductile metal. It requires to be explained how the presence of such carbide particles raises the stress required to produce initial deformation in the continuous matrix of ductile ferrite. An increase in the value for the stress up to which strain is proportional to stress is difficult to understand. Particles of other hard brittle materials such as slags, sulphides, etc., do not have the same effect, in that they leave the yield point and maximum stress unaltered, but the ductility is very much decreased. It seems, therefore, that the adhesion and cohesion between the ductile matter and the particular inclusions is an important factor. An interesting fact which requires explanation is the influence of cold work on the fatigue values. It seems peculiar that a process of plastic deformation should increase the resistance to fracture. Much has been written on the effect of grain size, but it is easy to overlook the fact that to modify grain size as the only variable is extremely difficult, if not impossible. The causes of the modification of grain size may well be the real cause of the apparent effect of grain size.

Prof. P. B. Haigh's contribution was of particular interest in that it could be considered that his observations postulated a resuscitation of the idea of stress in metals translating the crystalline to the amorphous phase. When a slip band is formed in a crystalline ductile metal, the increase in the volume from the crystalline to the amorphous state tends to produce fluid pressure in a core surrounded by increased shear stress, and the band tends to spread across planes of easy cleavage in the grain.

Mr. S. A. Main suggested that more work on the speed of testing and the influence of temperature might lead to further information on the main problem. He also referred to the characteristic appearance of slip bands which are visible under the microscope and are therefore of a different size from Gough's 'crystallites'. There can be little doubt that the characteristic separation of the bands has a fundamental bearing on the problem.

Sir Robert Hadfield, in a written contribution, said that when attending trials of projectiles against modern armour, he had often observed that there seemed to be little difference in the appearance of a fracture, as compared with the fractures met with under ordinary static or dynamic conditions at comparatively low velocities of impact. Nevertheless, there were instances of remarkable differences in behaviour of various steels according to the manner in which they were tested, that is, whether comparatively slowly or rapidly. Some materials like over-heated mild steel, tough under slow stressing, are quite brittle at moderate speeds of testing. Mild steel of ordinary good quality is tough at all normal speeds used in impact testing, but tends to break with a brittle fracture when attacked at high speeds with rifle bullets. With regard to the effect of low temperature, there seems to be no simple explanation of the different responses made by different metals. Thus the retention by nickel of its toughness at very low temperature is not simply explained by its particular type of cubic structure, namely, the face centred cubic, in contrast with that of iron, which is body centred cubic.

The discussion was an extremely valuable one, and has served to indicate many directions in which intensive investigation can usefully pro. ceed. 